Editorial

\title{
Nurses are not bystanders: A response to Paley
}

Paley's (2013) editorial in this journal is a welcome contribution to the discussion around the findings of the Francis report (2013) which provided a comprehensively damning account of organisational failure and lack of care in Stafford Hospital and Mid Staffordshire Foundation Trust which had been at the basis of many preventable deaths in the hospital between 2005 and 2009. The media response to the events and the findings of the report has been harsh, especially on nurses:

"Naïvely, we may have expected the public to rally behind their beloved nurses. Quite the contrary. It was now open season and former patients and families took to the press and internet in droves detailing their own nursing horror stories" (Darbyshire and McKenna, 2013, p:305).

Given this very public criticism and its potential effects on public confidence it is of particular importance that Paley dares to explore a defence of healthcare staff.

His analysis of the events leads him to conclude that not a failure of compassion but a series of contextual factors have led to the incidents in Stafford Hospital and also that 'these factors cannot be corrected or compensated for by teaching ethics, empathy and compassion to student nurses' (Paley, 2013, p. 1452). As part of his argument he invoked principles of social psychology and social cognition. We wholeheartedly agree with this perspective and would like to take the opportunity to examine it further. Specifically, we will look into the factors highlighted by Paley and will propose an alternative focus which leads us to a more nuanced conclusion in regard to the role of education in addressing the observed 'compassion deficit' in Stafford Hospital.

\section{Social Psychology Applied}

Paley states that there is an assumption in the Francis report that the nurses had a "lack of compassionate motivation" (p. 1451), and he is surprised that there is no attempt to make a distinction between compassionate motivation and compassionate behaviours. While he accepts that there was evidence of non-compassionate behaviour he disputes that the motivation behind this was essentially non-compassionate. While it is admirable to offer a defence in this way, the simple fact is that systematic investigation revealed evidence of non-compassionate behaviour and since it is the behaviour that will have impacted the patients, does it matter how nurses were motivated? In legal cases, intention often has a bearing on the sentence, so perhaps we should at least allow an exploration of this issue. So, why may nurses not have been lacking in compassionate motivation, intentions or values while exhibiting behaviours lacking in compassion?
This puzzling inconsistency leads Paley to look for social psychological explanations citing a well-known experiment on 'bystander apathy' (Latané and Darley, 1969). In common language, bystander apathy is a failure to help someone. It is of particular relevance to situations in which many people could have helped, but nobody did. In the experiment cited by Paley (Darley and Batson, 1973) seminaries were enticed to pass by a collapsed person. One group was told that they had a deadline. Another group was without a deadline. The ones with the deadline were much less likely to stop and help. No other characteristics contributed to that decision. The experiment demonstrates how easy it is to discourage the helping behaviours of people even if they are likely to have strong compassionate values or motivation.

Overall, there is significant empirical support for the bystander phenomenon (Aronson, 2012; see also Cherry, 2014), and it has been demonstrated consistently in situations in which there is no personal relationship between the person in need of help and the passive bystander (Fischer et al., 2011). Diffusion of responsibility is considered one of the core factors. The more passive bystanders there are, the less likely it is that someone will take action. Also, the bystander effect is most likely to occur in unusual situations or emergencies in which there is a need for an immediate response and the best response is unclear (Darley and Latané, 1968). Our problem with the bystander apathy explanation is that we wonder to what extent it applies to the nurses under consideration and scrutiny in the Francis report. After all, they were not passers-by, they know the patients personally, and they were trained, knowledgeable professionals who were employed and responsible to provide care, often in situations without many other bystanders present. Furthermore, while we may accept that if a person is rushed they may have an altered cognitive processing and "narrowed attention" (Paley, 2013 p. 1451), there is a significant difference between passing by someone in need of help in public, and consistent and repeated abuse and neglect in the work setting. Passers-by have an opt-out clause, after all they are passers-by, but no health care worker would be excused for simply passing a patient by (who is in need in some way). We don't believe that the experimental circumstances of the bystander are comparable with the health care setting. Nurses are placed into situations where they are expected (NMC, 2010) (and paid) to care in the long term. Repeated careless behaviour in such situations is more complex and therefore requires a more sophisticated analysis in which the dynamic relationship between cognitive and situational aspects is explored in more detail.

So while we don't want to give up on Paley's core notion of an inconsistency between compassion as a value or motivation and noncompassionate behaviour, we would like to provide an explanation for 
its emergence in enduring situations involving personal relationships, such as in a hospital, not in passers-by.

In our view, the principle that accounts most convincingly for this phenomenon is cognitive dissonance, defined by Festinger (1957) as the discomfort that ensues from holding two psychologically inconsistent notions at the same time. Revisions of this well researched paradigm (see Cooper, 2007) ${ }^{1}$ emphasise that this includes inconsistency between our behaviour and our values. Aronson (1999) suggests that dissonance is strongest when really important values are violated, including the belief in ourselves as good, smart, correct, etc. In nurses this would include the belief in themselves as compassionate. Core to the theory is that dissonance discomfort motivates efforts to reduce it. In the case of nurses who become aware that their care is inconsistent with their values, we would first and foremost expect efforts to improve their care. This would reduce the inconsistency and therefore the discomfort. However, if the behaviour, the non-compassionate care, has already taken place and cannot be reversed, it is more likely that rationalisations (Crigger and Meek, 2007), justifications or excuses will be formulated to reduce the dissonance. Such arguments will be affected by the hospital culture. If, as in Stafford Hospital, the prevailing wind turned in favour of cost cutting, time management and efficiency, aspects consistent with these values will be used. Typically, we will hear justifications such as 'there was just not enough time', 'the next patient was waiting', or 'if only we could afford more personnel, we could do better'.

The insidiousness of this shift is that once these justifications or excuses have been established by a person, future lapses in care will not lead to the same level of discomfort. As a result a gradual erosion of the quality of care is likely and a vicious cycle of increasingly deficient care may emerge. Once this process has affected a significant group of nurses, suboptimal care will become the norm and other mechanisms such as 'conformity' (Asch, 1956) will ensure that all involved behave accordingly. Typically those who can't reduce their dissonance around violating standards of care with justifications or excuses will leave the hospital and over the years their place will be taken by others who fit in better. If the hospital management is mostly concerned with saving money, they will most likely measure their achievements in financial terms. Any possible dissonance around care at management level will most likely be justified along the same lines as by the nurses or by denial.

While the core mechanisms seem simple, the way in which they are expressed in the dynamics of a hospital in decline makes them difficult to be aware of, as the social environment becomes a 'total reality' (Zimbardo et al., 2000) in which the participants lose perspective and where speaking out can be difficult (RCN, 2012). The inclination in hindsight to apportion blame rather than taking a more systemic view of matters is a common problem. This is for instance highlighted in investigations of industrial accidents whereby human error is pitched against organisational and structural failings. Suggesting that nurses need to receive better or more training in compassion is like shifting the blame for the problems arising in Mid Staffordshire away from the

\footnotetext{
${ }^{1}$ Cognitive Dissonance theory has been supported by an abundance of empirical research since Festinger (1957) introduced it. Cooper's overview (2007) and more recently Gawronski and Strack (2012) provide excellent background on the rich empirical support for dissonance theory and related models of cognitive inconsistency, which include studies on attitude and behavioural change, hypocrisy, moral judgement, and even neuroscience. Applications to health care and nursing are not plentiful. Most prominently, Totman (1976) applied dissonance theory to the placebo effect, and dissonance has also been linked with treatment of depression (Tryon \& Misurell, 2008) and eating disorders (Mitchell et al., 2007). Specific to nursing, Taylor and Bentley (2005) coined the term professional dissonance to understand conflict between practice and care values in mental health nursing. Crigger and Meek (2007) studied self-reconciliation after nursing mistakes with reference to cognitive dissonance. Fontenot et al. (2012) investigated how nursing educators experience dissonance, while De Vries (2008) applied the theory to the practice of the 'slow code' in cardiac care. A final example (Clark et al., 2004) seeks the application of dissonance to attitudes around smoking in nursing students.
}

organisation and on to the nurses. Similar to our suggestion in the above, Reason's (1997) approach is that industrial accidents occur due to a multiplicity of factors (including organisational influences, unsafe supervision, preconditions for unsafe acts, and the unsafe acts themselves). It would seem therefore that "When an adverse event occurs, it is important to determine how and why the defences failed, not who blundered" (Hinton-Walker et al., 2006 p.8). Dissonance is such a defence. It alerts nurses to inconsistencies between care standards and practice and therefore warns against 'careless care'. Problems occur when its alarm signals are silenced by dubious justifications and denial. However, because it plays out within the person as well as within the hospital organisation, it further complicates the question where responsibility lies when care fails.

\section{Nurse Education}

Notwithstanding the evidence for interactive mechanisms, suggesting a complex dance in which the hospital organisation and health care staff both play a role, the personal blame culture is alive and well. Its simplicity makes it a hot favourite also in the media. Paley can therefore be forgiven for providing a counterweight and dismissing as misguided the Francis Report's recommendation for an increased focus on teaching compassion. However, Paley's conclusion that nurses are already well motivated to be compassionate and hence teaching compassion may be fruitless is perhaps a bit rash.

Similar to the prioritisation issues in Stafford Hospital, where cost cutting became more important than compassionate care, nursing educators face a prioritisation issue in their universities. Fontenot et al.'s (2012) study suggests that as a result of this they experience dissonance and they 'feel torn by expectations of pursuing not one, but two or three work roles (p. 512).' In order to maintain credibility in the academic environment high quality research and publication output rank more highly than teaching. Moreover, focus on research grants, publication and other academic tasks are often at the expense of practice improvement. There are millions of pounds of public funding spent on research with yet no consistent evidence of improvement in practice. Rolfe (2012) points out that many scholars and academics have lost their way in the modern university. The philosophy and thrust of nursing faculties, schools and departments need to be scrutinised. Nursing staff are anecdotally already calling this into question (Booth, 2014). While there is no evidence to suggest that care deficits can be attributed to the move towards university based education (RCN, 2012) we should examine whether educational advances and professional progress in nursing care are at risk of being undermined by insufficient attention to care values (e.g. compassion, ethical practice, and person centred care). Perhaps nursing educators need to look at what they currently value most highly themselves and whether or not this contradicts the espoused values of the profession

Cognitive dissonance theory would suggest that by strengthening compassion values in education, the dissonance discomfort arising from a lapse in compassionate care would be higher. As a result the urgency to avoid or reduce the discomfort would increase. Within a supportive hospital this will most likely lead to continuous efforts by nurses to self-correct lapses in care instead of seeking rationalisations and justifications that accept non-compassionate care. Another element to be emphasised in the education would be an understanding of the mechanisms whereby erosion of care takes place and providing the students with the wherewithal to counter such processes. In practice, this can be achieved through a teaching collaboration between nursing and psychology lecturers (De Vries and Timmins, 2012) in which: (a) the dissonance mechanism is explained and applied to nursing care; (b) the compassion value is addressed and arguments are presented to strengthen it; (c) examples of nursing practices that are dissonant with compassion are discussed; and (d) common justifications for deficient care are explored and critiqued. To ensure a high impact, it is essential that students are actively contributing. 
Therefore, a scenario or enquiry based learning approach would be most suitable. This could serve as a virtual 'inoculation' against compassion erosion and reduce the chances that the problems as occurred in Stafford Hospital would occur elsewhere. While it is improper to single out nurses for blame, it is also improper to suggest that they (and their educators) are not in a position to influence the practices in the hospitals in which they work.

\section{Conclusion}

While agreeing broadly with Paley that blaming the nurse for the issues such as occurred in Stafford Hospital is not the answer, our application of cognitive dissonance theory rather than bystander apathy to the issues has led to different conclusions. In our view a reorientation of nursing faculty towards a culture that places compassion and excellence in care as the priority may play a role in preventing the emergence of scandals such as in Stafford Hospital. While it is understood that toxic cultures can develop whereby an "institutional heartlessness" can develop and be spread to others (Wilkinson cited in Chambers and Ryder, 2009 P.2), nursing students and nurses are not passers-by and need to take their responsibility seriously. The core values of nursing need to be re-established and affirmed at all levels of service and delivery, with mechanisms for honest reflection on practice integral to service delivery. These need to be substantiated with a renewed emphasis on professional confidence and assertion (which is undermined by the current media debate). There must also be an open, honest and transparent health care culture where integrity, and sensitivity flourish and nursing students need to be prepared for this with a good grounding in ethics, empathy and compassion. In tandem with this, the mechanisms at the core of compassion erosion as outlined by us should be recognised and addressed in nursing education and by doing so nursing students can be much better prepared, and develop the necessary resilience to remain compassionate.

\section{References}

Aronson, E., 1999. Dissonance, hypocrisy and the self concept. In: Harmon-Jones, E., Mills, J. (Eds.), Cognitive Dissonance: Progress on a Pivotal Theory in Social Psychology. American Psychological Association, Washington DC, pp. 103-126.

Aronson, E., 2012. The Social Animal, 12th edn. Worth Publishers, New York.

Asch, S.E., 1956. Studies of independence and conformity: I. A minority of one against a unanimous majority. Psychol. Monogr. 70, 1-70.

Booth, B., 2014. How a university's attitudes destroy professional practice. Nurs. Times $110(8), 11$.

Chambers, C., Ryder, E., 2009. Compassion and Caring in Nursing. Radcliffe Publishing, Oxford.

Cherry, K., 2014. The Bystander Effect. Why Bystanders Sometimes Fail to Help. About. com Psychology.available at: http://psychology.about.com/od/socialpsychology/a/ bystandereffect.htm (accessed 9th February 2014).

Clark, E., McCann, T., Rowe, K., Lazenbatt, A., 2004. Cognitive dissonance and undergraduate nursing students' knowledge of, and attitudes about, smoking. J. Adv. Nurs. 46 (6), 586-594.

Cooper, J., 2007. Cognitive Dissonance: Fifty Years of a Classic Theory. Sage, London.

Crigger, N.J., Meek, V.L., 2007. Towards a theory of self-reconciliation following mistakes in nursing practice. J. Nurs. Scholarsh. 3 (2), 177-183.

Darbyshire, P., McKenna, L., 2013. Nursing's crisis of care: what part does nursing education own? Nurse Educ. Today 33, 305-307.

Darley, J.M., Batson, C.D., 1973. From Jerusalem to Jericho: a study of situational and dispositional variables in helping behaviour. J. Pers. Soc. Psychol. 27 (1), 100-108.
Darley, J.M., Latané, B., 1968. Bystander intervention in emergencies: diffusion of responsibility. J. Pers. Soc. Psychol. 8, 377-383.

De Vries, J.M.A., 2008. Cognitive dissonance theory applied to CPR, DNAR, and the practice of slow codes. Br. J. Card. Nurs. 3 (12), p565-p570.

De Vries, J.M.A., Timmins, F., 2012. Psychology teaching in nursing education: a reflection on approaches, issues, and contemporary practice. Nurse Educ. Pract. 12 (6), p316-p321.

Festinger, L., 1957. A Theory of Cognitive Dissonance. Stanford University Press, Palo Alto, CA.

Fischer, P., Krueger, J.I., Greitemeyer, T., Vogrincic, C., Kastenmüller, A., Frey, D., Heene, M., Wicher, M., Kainbacher, M., 2011. The bystander-effect: a meta-analytic review on bystander intervention in dangerous and non-dangerous emergencies. Psychol. Bull. 137 (4), 517-537.

Fontenot, H.B., Hawkins, J.W., Weiss, J.A., 2012. Cognitive dissonance experienced by nurse practitioner faculty. J. Am. Acad. Nurse Pract. 24 (8), 506-513.

Francis, R., 2013. Report of the Mid Staffordshire NHS Foundation Trust Public Inquiry. The Stationery Office, Norwich (Available at: http://www.midstaffspublicinquiry. com accessed 7th February 2014).

Gawronski, B., Strack, F. (Eds.), 2012. Cognitive Consistency: A Fundamental Principle in Social Cognition. The Guilford Press, New York/London.

Hinton-Walker, P., Carlton, G., Holden, L., Stone, P.W., 2006. The intersection of patient safety and nursing research. In: Fitzpatrick, J.J., Stone, P.W., Hinton-Walker, P. (Eds.), Annual Review of Nursing Research. Focus on Patient Safety, vol. 24. Springer Publishing, pp. 8-9.

Latané, B., Darley, J., 1969. Bystander apathy. Am. Sci. 57, 244-268.

Mitchell, K.S., Mazzeo, S.E., Rausch, S.M., Cooke, K.L., 2007. Innovative interventions for disordered eating: evaluation dissonance-based and yoga interventions. Int. J. Eat. Disord. 40 (2), 120-128.

Nursing, Midwifery Council (NMC), 2010. Standards for Pre-registration Nursing Education. Nursing and Midwifery Council, London.

Paley, J., 2013. Social psychology and the compassion deficit. Nurse Educ. Today 33, 1451-1452.

RCN, 2012. Quality with compassion: the future of nursing education. Report of the Willis Commission on Nursing Education, 2012. The Royal College of Nursing, London (Available at: http://www.williscommission.org.uk/recommendations accessed 19th May 2014).

Reason, J., 1997. Managing the Risks of Organizational Accidents. Ashgate, Aldershot Brookfield USA.

Rolfe, G., 2012. Fast food for thought: how to survive and thrive in the corporate university. Nurse Educ. Today 32 (7), 732-773.

Taylor, M.F., Bentley, K.J., 2005. Professional dissonance: colliding values and job tasks in mental health practice. Community Ment. Health J. 41 (4), 469-480.

Totman, R.G., 1976. Cognitive dissonance and the placebo response. Eur. J. Soc. Psychol. 5 , 119-125.

Tryon, W.W., Misurell, J.R., 2008. Dissonance induction and reduction: a possible principle and connectionist mechanism for why therapies are effective. Clin. Psychol. Rev. 28, 1297-1309.

Zimbardo, P.G., Maslach, C., Haney, C., 2000. Reflections on the Stanford prison experiment: genesis, transformations, consequences. In: Blass, T. (Ed.), Obedience to Authority: Current Perspectives on the Milgram Paradigm. Erlbaum, Mahwah, N.J., pp. 193-237.

Fiona Timmins PhD, MSC, MA, FFNRCSI, BNS, BSc (Open) RNT, RGN Associate Professor Corresponding author at: School of Nursing and Midwifery, 24 D'Olier St., Trinity College Dublin, Dublin 2, Ireland. Tel.: +3531896 3699; fax: + 3518963001. E-mail address: Fiona.timmins@tcd.ie.

Jan M.A. de Vries PhD, MSc, BSc Assistant Professor and Psychology Subject Leader School of Nursing and Midwifery, Trinity College Dublin, Ireland

11 March 2014 Available online xxxx 